\title{
Polyclinics and polysystems: evolving ambiguity, evidence required
}

The current debate about healthcare system configuration is symbolised in the UK by the move towards delivery of primary care through polysystems. ${ }^{1}$ Polysystems are an extension of the polyclinic proposals originally outlined by Healthcare for London, ${ }^{2}$ and subsequently taken up across the UK under the name 'GP-led health centres'. ${ }^{3}$ This Editorial aims to address two key questions: 'What is a polyclinic/polysystem?' and 'What is the evidence supporting wide-scale implementation at a time when economic resources are scarce?'

GP-led health centres were conceived in 2007 for the UK as large buildings, to be located freestanding in the community or next door to accident and emergency (A\&E) departments. ${ }^{2}$ A Framework for Action refers to increased diagnostic services, an expansion of the workforce (social advisors, consultants, and physiotherapists) serving a population of 50 000. GP surgeries would be located within the building, either as one large surgery or as a number of separate surgeries under the same roof. Another permutation, which received less media attention at the time, was for existing GP surgeries to 'orbit' the polyclinics, that is a 'hub-and-spoke' model. This last model was similar to the federated model proposed by the Royal College of General Practitioners, ${ }^{4}$ and it is this model that now prevails in Healthcare for London's 2010 plans for polysystems. ${ }^{1}$

The debate about polyclinics, which has tended to occur at clinical and academic levels, rather than at a planning level, has focused on their definition, with many arguing that the proposals were nothing new, having existed internationally and in similar forms within the UK. ${ }^{5}$ Such discussions arguably eclipse a more pressing question: how is primary care best configured? Two reports attempt to address this issue: Under One Roof, and Integrated Primary Care Centres and Polyclinics.

\section{UK AND BEYOND}

The King's Fund report Under One Roof, published before the first wave of polyclinics opened, focuses on the largest scale version of the polyclinic, where key services are located in a single building. ${ }^{6}$ By analysing government policy and quoting international examples from countries such as Russia, Cuba, and Germany where various polyclinic formations exist, the authors examine how such a model may work in the UK. They argue that 'developing new pathways, technologies and ways of working' are more important than buildings for integrating primary and secondary care. ${ }^{6}$ The report also highlighted the significant workforce implications, for example; having enough specialists to work in polyclinics as well as covering hospital care. Importantly, they conclude that such shifts in configuration are unlikely to be cheaper than existing systems. ${ }^{6}$ Under One Roof recommends that primary care trusts should not concentrate general practice services on one site and should consider using a hub-and-spoke model, which is now the prevailing configuration for polysystems.

Efforts to integrate primary care services are also underway in other countries. Integrated Primary Care Centres and Polyclinics ${ }^{7}$ is an academic Australian report from a country where 'GP Super Clinics' are being built. Comparing different modes of provision, the report defines three models of integrated primary care:

(1) 'Extended general practice' - general practices that 'have been developed to the point where they can be said to be offering multidisciplinary primary care rather than just primary medical care';

(2) 'Broader primary health care models' which address 'the needs of a disadvantaged community or group'; and

(3) 'Centres with a strong focus on secondary care' - 'where the focus tends to be on integration of general practice with secondary care rather than within primary care'.

Authors of the Integrated Primary Care Centres and Polyclinics ${ }^{7}$ systematically reviewed the literature to assess the effectiveness of integrated primary healthcare centres looking at 'patterns of health service provision, access, use of services, quality of care outcomes, health outcomes, and economic outcomes'. Most of the evidence they found was limited to data from case studies, surveys, and studies comparing outcomes without controlling for the intervention in question. The report concludes that UK private medical services practices are responsive, are able to meet the needs of the community, and show some increased access for neglected groups, such as the homeless. No data on the economic outcomes for the models described was found outside the US. The report commented that New Zealand, with its broader primary health care models, had a particularly strong focus on equity.

\section{WHERE NOW?}

Both these reports are relevant to the polysystem debate. However, the report by The King's Fund examines the model 'under one roof' with little analysis of how hub-and-spoke systems might work, or how such a model would differ significantly from existing networks of care; for example, GPs satellites that already orbit local hospitals. The Australian Primary Health Care Research Institute report ${ }^{7}$ considered only private medical services practices in their analysis of UK general practice, whereas the vast majority of UK surgeries have general medical services contracts, ${ }^{8}$ and many of these would fulfil the criteria of integration used in their report. In the UK, polyclinics and polysystems, like many health centres before them, can be seen as an attempt to reduce the fragmentation of the health service. It could, however, be argued that 
a publicly-funded comprehensive health service, with well-demarcated referral pathways is in itself an example of integration.

Healthcare for London defines a polysystem as:

'... a primary care-led approach to healthcare, designed to localise care wherever possible. Each polysystem will have a polyclinic as its "hub", but also with a proportion of care delivered at home, in linked GP "spoke" practices and/or locations in the community."

The financial motivations behind the plans are clear, as Healthcare for London quotes the predicted deficit of $£ 3.8$ billion for NHS London by 2016/17, which is forecast to rise. 'Polysystems' appear to incorporate some of the King's Fund recommendations by avoiding centralising of GP services, adopting a hub-and-spoke model, strengthening commissioning roles so services reflect local needs, and quickly decommissioning existing services to avoid duplication. ${ }^{1}$

The proposals are not without criticism. The BMA report On The Brink challenges the assumption that the polyclinic/ polysystem plans will reduce $A \& E$ attendances by $50 \%$, and questions the lack of detail on costing, and the implications for hospital survival. ${ }^{9}$ Polysystems appear to encourage an explicit expansion of the marketplace for health care, which may not be conducive to fostering integration. As the Healthcare for London strategic plan states:

'To deliver polysystems, a set of business models needs to be created that allows primary care clinicians to employ secondary care professionals and deliver polysystems, and allows acute providers to employ GPs and provide primary care services, thus allowing commissioners to contract easily for the service model.'

Despite a lack of compelling evidence that the proposed changes will deliver their intended benefits (for example, increasing accessibility and quality), ${ }^{1}$ a significant reconfiguration of UK primary and secondary care is underway. A report from the World Health Organization has argued that more research is needed into primary care systems: 'There are few transnational or pre and post-intervention studies. ${ }^{10}$

The current evaluation of polyclinics coordinated by Healthcare for London has a strong focus on service delivery and commissioning as opposed to examining the model itself. ${ }^{11}$ Researchers could have used this opportunity to tease out and evaluate, with scientific rigour, the many components behind the polyclinic proposals. ${ }^{12,13}$ There is an urgent need for such research to contribute to the unresolved debate about primary healthcare configuration in the UK and thus inform debate about other healthcare systems around the world.

\section{Patrick Hutt,}

Clinical Associate and Camden Salaried GP, UCL Research Department of Primary Care and Population Health, Royal Free and University College Medical School, London.

\section{Surinder Singh,}

Senior Lecturer in General Practice, UCL Research Department of Primary Care and Population Health, Royal Free and University College Medical School, London.

\section{Michael Modell,}

Emeritus Professor of Primary Health Care, UCL Research Department of Primary Care and Population Health, Royal Free and University College Medical School, London.

\section{Irwin Nazareth,}

Professor of Primary Care and Population Health and Head of Department, UCL Research Department of Primary Care and Population Health, Royal Free and University College Medical School, London.

\section{Provenance}

Freely submitted; not peer reviewed.

\section{REFERENCES}

1. Healthcare for London, NHS London. Delivering healthcare for London: an integrated strategic plan 2010-2015. London: NHS London, 2010.

2. Healthcare for London. A framework for action. London: Healthcare for London, 2007. http://www.healthcareforlondon.nhs.uk/assets/Publicati ons/A-Framework-for-

Action/aFrameworkForAction.pdf (accessed 12 May 2010)

3. Department of Health. Equitable access to primary medical care services (EAPMC): procurement at PCTs. London: Department of Health.

http://www.dh.gov.uk/en/Procurementandproposals/Pr ocurement/ProcurementatPCTs/index.htm (accessed 12 May 2010).

4. Lakhani M, Baker M, Field S. The future direction of general practice: a road map. London: Royal College of General Practitioners, 2007.

http://www.rcgp.org.uk/PDF/Roadmap_embargoed\%2 011 am\%2013\%20Sept.pdf (accessed 12 May 2010).

5. Finch R. When is a polyclinic not a polyclinic? BMJ 2008; 336: 916-918.

6. Imison C, Naylor C, Maybin B. Under one roof: will polyclinics deliver integrated care? London: King's Fund, 2008.

http://www.kingsfund.org.uk/document.rm?id=7699

7. Powell Davies PG, McDonald J, Jeon Y-H, et al. Integrated primary health care centres and polyclinics: a rapid review. Centre for Primary Health Care and Equity UNSW and Australian Primary Health Care Research Institute, Sydney; 2009.

8. Royal College of General Practitioners. Key demographic statistics from UK general practice. London: Royal College of General Practitioners, 2006. http://www.rcgp.org.uk/pdf/ISS_FACT_06_KeyStats.pd $f$ (accessed 12 May 2010).

9. Lister J. London's NHS: on the brink. London: British Medical Association, 2009.

http://www.bma.org.uk/images/onthebrinkreport2010_ tcm41-193388.pdf (accessed 12 May 2010).

10. Atun R. What are the advantages and disadvantages of restructuring a health care system to be more focused on primary care services? Copenhagen: WHO Regional Office For Europe, 2004. http://www.euro.who.int/document/e82997.pdf (accessed 12 May 2010).

11. Healthcare for London. The evaluation of polyclinics: call for proposals. London: Healthcare for London, 2009.

http://www.healthcareforlondon.nhs.uk/assets/Publicati ons/Polyclinics/The-Evaluation-of-Polyclinics-2.pdf (accessed 12 May 2010).

12. Campbell M, Fitzpatrick R, Haines A, et al. Framework for design and evaluation of complex interventions to improve health. BMJ 2000; 321: 694-696.

13. Craig P, Dieppe P, Macintyre S, et al. Developing and evaluating complex interventions: the new Medical Research Council guidance. BMJ 2008; 337: al655.

DOI: 10.3399/bjgp10X502083

\section{ADDRESS FOR CORRESPONDENCE}

\section{Patrick Hutt}

UCL Research Department of Primary Care and Population Health, Royal Free and University College Medical School, Rowland Hill Street, London NW2 2PF. E-mail p.hutt@ucl.ac.uk 